\title{
Scenedesmaceae (Chlorophyta, Chlorophyceae) de duas áreas do Pantanal dos Marimbus (Baiano e Remanso), Chapada Diamantina, Estado da Bahia, Brasil ${ }^{1}$
}

\author{
Geraldo José Peixoto Ramos ${ }^{2,4}$, Carlos Eduardo de Mattos Bicudo ${ }^{3}$ e Carlos Wallace do Nascimento Moura ${ }^{2}$
}

Recebido: 6.01.2015; aceito: 6.05.2015

\begin{abstract}
Scenedesmaceae (Chlorophyta, Chlorophyceae) from two areas of the Marimbus Pantanal (Baiano and Remanso), Chapada Diamantina, Bahia State, Brazil). This work deal with the taxonomy of the Family Scenedesmaceae from Marimbus Pantanal, Environmental Protection Area Marimbus-Iraquara, Chapada Diamantina, Bahia State, Brazil. Samples from the periphyton and plankton were collected in two areas of the Marimbus Pantanal (Baiano and Remanso) during the dry season (April, June, and August 2011) and the rainy season (October, December 2011, and February 2012). This study describes 27 taxa, including 18 additions to the phycological flora of Bahia.
\end{abstract}

Keywords: coccoid green algae, Coelastrum, Desmodesmus, Scenedesmus, taxonomy

RESUMO - (Scenedesmaceae (Chlorophyta, Chlorophyceae) de duas áreas do Pantanal dos Marimbus (Baiano e Remanso), Chapada Diamantina, Estado da Bahia, Brasil). Este estudo trata do estudo taxonômico da família Scenedesmaceae do Pantanal dos Marimbus, Área de Proteção Ambiental Marimbus-Iraquara, Chapada Diamantina, Bahia, Brasil. As amostras provenientes do perifíton e do plâncton foram coletadas em duas áreas do Pantanal dos Marimbus (Baiano e Remanso), durante o período seco (abril, junho e agosto de 2011) e o período chuvoso (outubro, dezembro de 2011 e fevereiro de 2012). São descritos 27 táxons, dos quais 18 são adições a flora ficológica da Bahia.

Palavras-chave: algas verdes cocoides, Coelastrum, Desmodesmus, Scenedesmus, taxonomia

\section{Introdução}

As Scenedesmaceae (Chlorophyceae) englobam os indivíduos unicelulares que formam cenóbios em um ou mais planos. É considerada a maior família das algas verdes cocoides que habitam os ambientes aquáticos continentais (Krienitz \& Bock 2012). Apresentam parede celular constituída por uma camada interna de celulose e uma ou mais camadas externas de esporopolenina, estas podendo apresentar diversas ornamentações como espinhos, costelas ou granulações (Atkinson et al. 1972, Comas 1996). A reprodução ocorre por autósporos formando autocenóbios no interior da célula-mãe, os quais são liberados pelo rompimento da parede (Nogueira 1991).

Ao longo dos últimos 15 anos, diversos estudos foram realizados nas Scenedesmaceae visando investigar as suas relações filogenéticas. An et al. (1999), baseados nos resultados obtidos de estudos moleculares (ITS-2 rDNA) e morfológicos de Scenedesmus Meyen, separaram os gêneros Scenedesmus e Desmodesmus (Chodat) S.S. An, Friedly \& E. Hegewald, este último anteriormente enquadrado como subgênero de Scenedesmus. Amparado nos dados dos autores acima, Hegewald (2000) propôs novas combinações para o gênero Desmodesmus. Tsarenko em Tsarenko \& Petlevanny (2001) elevou Scenedesmus subgênero Acutodesmus Hegewald à categoria de gênero, Acutodesmus (Hegewald) Tsarenko.

Hegewald et al. (2010), analisando as sequências e as estruturas secundárias do gene ITS-2 rRNA de alguns táxons de Scendesmaceae e Coelastraceae, observaram que a família Coelastraceae é

1. Parte da Dissertação de Mestrado do primeiro Autor

2. Universidade Estadual de Feira de Santana, Programa de Pós-Graduação em Botânica, Av. Transnordestina, s/n, Novo Horizonte, 44036-900 Feira de Santana, Bahia, Brasil

3. Instituto de Botânica, Núcleo de Pesquisa em Ecologia, Av. Miguel Estéfano, 3687, 04301-902 São Paulo, SP, Brasil

4. Autor para correspondência: geraldojpr@gmail.com 
monofilética e enquadraram seus representantes em Scenedesmaceae, na subfamília Coelastroidae. Neste estudo, os autores propuseram ainda dois novos gêneros, Comasiella E. Hegewald, M. Wolf, A. Keller, Friedl \& Krienitz e Pectinodesmus E. Hegewald, M. Wolf, A. Keller, Friedl \& Krienitz. Recentemente, Hegewald et al. (2013), baseados em estudos em sequências do gene rRNA (ITS1/5.8S/ ITS2), morfologia celular e ultraestrutura da parede de representantes de Scenedesmaceae, descreveram dois novos gêneros na família: Verrucodesmus E. Hegewald e Chodatodesmus E. Hegewald, C. Bock et Krienitz.

A família Scenedesmaceae é composta por 30 gêneros, dos quais 13 estão morfologicamente e filogeneticamente bem delimitados (Hegewald et al. 2010, Krienitz \& Bock 2012, Bock et al. 2013, Hegewald et al. 2013). Recentemente o gênero Tetrastrum, anteriormente posicionado em Scenedesmacae por Hegewald et al. (2010), foi transferido para Trebouxiophyceae por Bock et al. (2013). Neste último estudo, ao correlacionarem dados moleculares (gene SSU rDNA) com caracteres morfológicos e ontogenéticos de algas verdes crucigenioides, os autores transferiram algumas espécies de Tetrastrum Chodat para o gênero Lemmermania Chodat (Trebouxiophyceae), ao passo que outras como Tetrastrum heteracanthum (Nordst.) Chodat e T. staurogeniaeforme (Schröder) Lemmermann foram posicionadas em uma nova linhagem de Oocystis Nägeli ex A. Braun em Trebouxiophyceae.

A família Scenedesmacae apresenta uma ampla distribuição e é comumente reportada nos mais diversos ambientes aquáticos continentais do Brasil (Menezes et al. 2014), geralmente dominando a comunidade com maior riqueza específica (Felisberto et al. 2001, Domingues \& Torgan 2012). No Estado da Bahia, o conhecimento da família está restrito a alguns trabalhos de cunho ecológico (Fuentes et al. 2010, Severiano et al. 2012), fisiológico (Mendes et al. 2012) e taxonômico (Martins et al. 1991, Ramos et al. 2014). Contudo, não existem estudos específicos de Scenedesmacae, sendo o presente, portanto, pioneiro no Estado.

O presente estudo teve como objetivo realizar o levantamento florístico da Família Scenedesmaceae em duas áreas do Pantanal dos Marimbus (Baiano e Remanso), Chapada Diamantina, Bahia.

\section{Material e métodos}

O Pantanal dos Marimbus, localizado na porção leste do Parque Nacional da Chapada Diamantina,
Bahia, corresponde a uma extensa área plana e pantanosa sujeita a inundações periódicas pelos rios da região. $\mathrm{O}$ Pantanal é subdividido em quatro áreas: Marimbus do Remanso (localizado ao norte, no Município de Lençóis), Marimbus da Fazenda Velha, Marimbus do Ferreira e Marimbus do Baiano (localizado ao sul, no Município de Andaraí), todas interligadas pelo rio Santo Antônio (Ramos et al. 2014) (figura 1).

As unidades amostrais foram coletadas durante o período seco (abril, junho e agosto de 2011) e período chuvoso (outubro, dezembro de 2011 e fevereiro de 2012) de modo aleatório em duas áreas do Pantanal dos Marimbus (Baiano e Remanso) (12³9'13" a $12^{\circ} 46^{\prime} 48^{\prime \prime} \mathrm{S} ; 4^{\circ} 17^{\prime} 00^{\prime \prime}$ a $\left.41^{\circ} 21^{\prime} 25^{\prime \prime} \mathrm{W}\right)$. Todas as coletas foram realizadas utilizando técnicas para o estudo taxonômico de algas de águas continentais (Bicudo \& Menezes 2006).

Os limites métricos dos táxons foram obtidos utilizando uma ocular micrométrica e as microfotografias foram obtidas com uma câmera digital (SONY, modelo Cyber-shot DSC-W7) acoplada ao microscópio óptico LEICA, modelo DMLS2. As medidas (em $\mu \mathrm{m})$ foram representadas pelas abreviaturas: compr.: comprimento; larg.: largura; diam.: diâmetro. Os táxons foram identificados
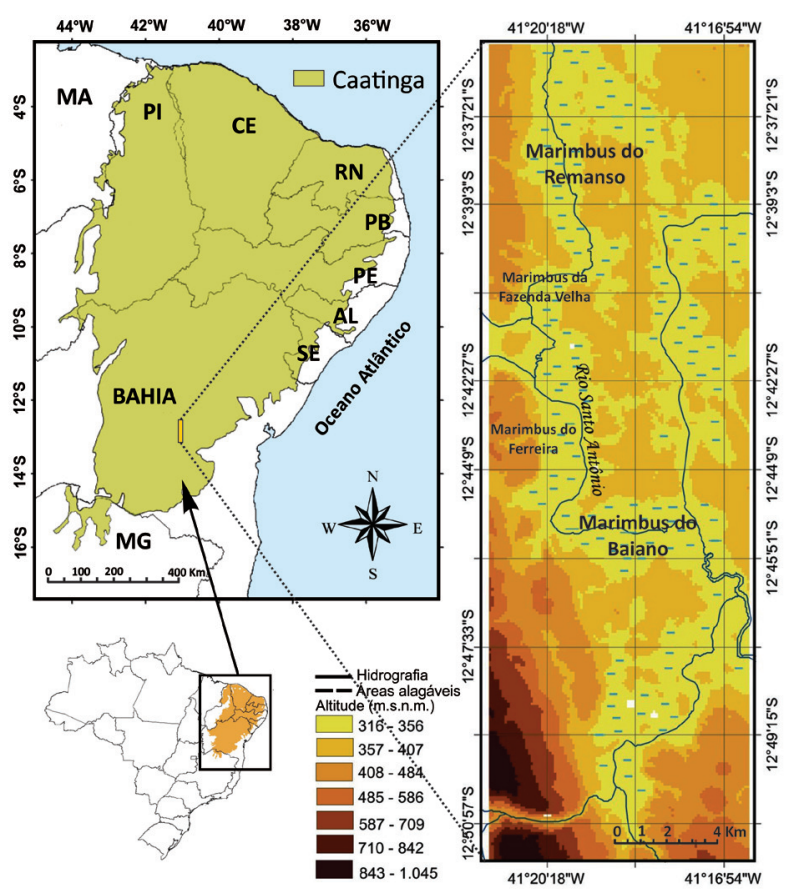

Figura 1. Mapa da localização do Pantanal de Marimbus, Chapada Diamantina, BA, Brasil (modificado de Ramos et al. 2014).

Map of the Marimbus Pantanal, Chapada Diamantina, Bahia State, Brazil (modified from Ramos et al. 2014). 
baseados em literatura especializada; o sistema de classificação adotado segue Hegewald et al. (2010) acrescido de atualizações de Hegewald et al. (2013) para o gênero Verrucodesmus.

As amostras foram preservadas em solução de Transeau conforme Bicudo \& Menezes (2006) e, depositadas na coleção líquida do Herbário da Universidade Estadual de Feira de Santana (HUEFS).

\section{Resultados e Discussão}

Durante o levantamento florístico da família Scenedesmaceae (Chlorophyceae) em duas áreas do Pantanal dos Marimbus (Baiano e Remanso) foram identificados 27 táxons:

Scenedesmaceae

Subfamília Coelastroideae

Chave artificial para identificação das morfoespécies de Coelastrum registradas $\mathrm{n}$ o Pantanal dos Marimbus:

1. Células unidas por processos conectivos

2. Células com 1 apêndice cônico-truncado no ápice C. pulchrum

2. Células sem apêndices no ápice

3. Células unidas por até 4 processos

4. Células subtriangulares ...... C. proboscideum

4. Células subquadráticas ............ C. cruciatum

3. Células unidas por mais de 4 processos

5. Células em vista lateral ovoides a cuneiformes C. pseudomicroporum

5. Células em vista lateral arredondadas .... ......................................... . indicum

1. Células destituídas de processos conectivos

6. Células esféricas em vista lateral ... C. microporum 6. Células ovoides em vista lateral ...... C. astroideum

Coelastrum astroideum De Notaris, Elem. Desmid. Ital. 80, pl 9, fig. 93. 1867.

Figura 2 a

Cenóbio esférico à irregular, 8-16 células unidas diretamente pela parede celular (sem processos conectivos); células ovoides em vista lateral, circulares em vista apical; espaços intercelulares reduzidos ou até ausentes; parede celular levemente espessada na face livre; cloroplastídio 1, parietal, 1 pirenoide. Dimensões: cenóbio 18-22,5 $\mu \mathrm{m}$ diâm., célula 5-6,5 $\mu \mathrm{m}$ diâm.
Material examinado: BRASIL. BAHIA: Andaraí, Marimbus do Baiano, 9-XII-2011, C.A. Ribeiro \& G.J.P. Ramos s.n. (HUEFS185388).

Hábitat: perifíton.

Segundo Nogueira (1991), C. astroideum difere das demais espécies do gênero por apresentar células ovoides em vista lateral e carecer de processos conectivos. Pode ser confundida, principalmente, com C. microporum Nägeli e C. pseudomicroporum Koršikov, diferindo da primeira que apresenta células esféricas em vista lateral, e da segunda que possui processos curtos interligando as células. Os espécimes do Pantanal dos Marimbus apresentaram dimensões celulares relativamente menores quando comparadas com as de Sant'Anna (1984), no entanto, estão de pleno acordo com os limites métricos registrados por Komárek \& Fott (1983), Nogueira (1991) para material do Rio de Janeiro e Tsarenko \& John (2011) para as Ilhas Britânicas.

Coelastrum cruciatum Schmidle, Bot. Centralbl. 8: 418. 1900.

Figura $2 \mathrm{~b}$

Cenóbio esférico, 8-32 células unidas por 4 processos cônico-truncados dispostos em forma de cruz; células arredondadas em vista lateral, subquadráticas em vista apical; espaços intercelulares retangulares a esféricos; parede celular lisa, espessamento apical; cloroplastídio 1, parietal, 1 pirenoide. Dimensões: cenóbio 40-68,8 $\mu \mathrm{m}$ diâm., célula 13,5-15 $\mu \mathrm{m}$ diâm.

Material examinado: BRASIL. BAHIA: Lençóis, Marimbus do Remanso, 2-IV-2011, C.W.N. Moura \& G.J.P. Ramos s.n. (HUEFS178350); 30-VI-2011, C.A. Ribeiro \& G.J.P. Ramos s.n. (HUEFS178394); 10-XII-2011, C.A. Ribeiro \& G.J.P. Ramos s.n. (HUEFS185398, HUEFS185399).

Hábitat: plâncton, perifíton.

Segundo Comas (1996), C. cruciatum é morfologicamente próximo de $C$. indicum, mas este difere por apresentar vista apical da célula poliédrica, com 5-6 processos celulares. As populações analisadas estão de pleno acordo com as descrições, medidas e ilustrações apresentadas por Komárek \& Fott (1983), Komárek (1983) e Comas (1996) para Cuba e Hentschke \& Torgan (2010a) para o Rio Grande do Sul. Segundo Comas (1996), a espécie é conhecida apenas para a região tropical do globo, sendo encontrada desde ambientes oligotróficos até 
eutróficos. Esse é o primeiro registro da espécie no Estado da Bahia.

Coelastrum indicum W.B. Turner, Alg. Ind. oriente.:

161, fig.11. 1893.

Figura 2 c-d

Cenóbio esférico, 16 ou 32 células unidas por 5-6 processos; células arredondadas em vista lateral, poliédricas em vista apical, espaços intercelulares triangulares a esféricos; parede celular lisa, espessamento apical; cloroplastídio 1, parietal, 1 pirenoide. Dimensões: cenóbio 30-55 $\mu \mathrm{m}$ diâm., célula 12-18 $\mu \mathrm{m}$ diâm.

Material examinado: BRASIL. BAHIA: Andaraí, Marimbus do Baiano, 1-IV-2011, C.W.N. Moura \& G.J.P. Ramos s.n. (HUEFS178332, HUEFS178335); 29-VI-2011, C.A. Ribeiro \& G.J.P. Ramos s.n.
(HUEFS178364, HUEFS 178366); 19-VIII-2011, C.W.N. Moura \& G.J.P. Ramos s.n. (HUEFS185348, HUEFS185350, HUEFS185355); 26-X-2011, C.A. Ribeiro \& G.J.P. Ramos s.n. (HUEFS185372); 9-XII-2011, C.A. Ribeiro \& G.J.P. Ramos s.n. (HUEFS185388, HUEFS185390, HUEFS185396, HUEFS185397); 10-II-2012, C.A. Ribeiro \& G.J.P. Ramos s.n. (HUEFS185412, HUEFS185416); Lençóis, 2-IV-2011, Marimbus do Remanso, 10-XII-2011, C.A. Ribeiro \& G.J.P. Ramos s.n. (HUEFS185402, HUEFS185403, HUEFS185406); 11-II-2012, C.A. Ribeiro \& G.J.P. Ramos s.n. (HUEFS185420).

Hábitat: plâncton, perifíton.

Coelastrum indicum é morfologicamente próximo de C. cruciatum, entretanto, este é distinto por apresentar quatro processos dispostos crucialmente e

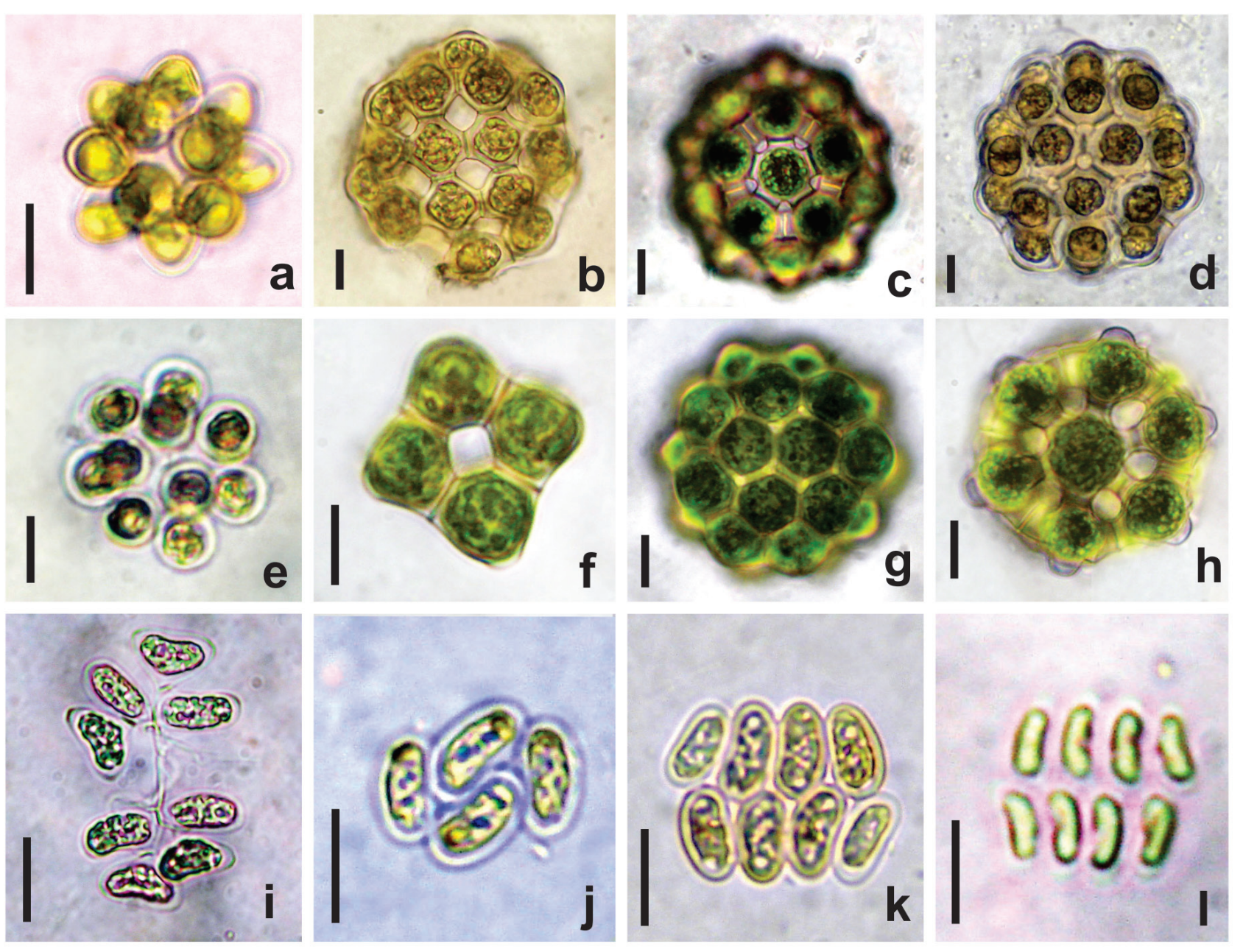

Figura 2 a. Coelastrum astroideum. b. C. cruciatum. c-d. C. indicum. e. C. microporum. f. C. proboscideum. g. C. pseudomicroporum. h. C. pulchrum. i. Dimorphococcus lunatus. j-1. Comasiella arcuata var. platydisca. Barras $=10 \mu \mathrm{m}$.

Figure 2 a. Coelastrum astroideum. b. C. cruciatum. c-d. C. indicum. e. C. microporum. f. C. proboscideum. g. C. pseudomicroporum. h. C. pulchrum. i. Dimorphococcus lunatus. j-1. Comasiella arcuata var. platydisca. Bars $=10 \mu \mathrm{m}$. 
células subquadráticas em vista apical. As descrições, medidas e ilustrações dos exemplares do Pantanal dos Marimbus concordam com os estudados por Komárek \& Fott (1983), Comas (1996) e Rodrigues et al. (2010). Segundo Comas (1996), a espécie é cosmopolita, porém, mais frequente nos trópicos.

Coelastrum microporum Nägeli. in A. Braun, Alg.

Unicell: 70 adn., 73. 1855

Figura $2 \mathrm{e}$

Cenóbio esférico, 8-16-32 células unidas diretamente por suas paredes; células esféricas, sem processos conectivos, pequenos espaços intercelulares triangulares ou retangulares; parede celular lisa, sem espessamento apical, cloroplastídio 1, parietal, 1 pirenoide central. Dimensões: cenóbio 30-38 $\mu \mathrm{m}$ diâm., célula 6,2-8,8 $\mu \mathrm{m}$ diâm.

Material examinado: BRASIL. BAHIA: Andaraí, Marimbus do Baiano, 1-IV-2011, C.W.N. Moura \& G.J.P. Ramos s.n. (HUEFS178326, HUEFS178329, HUEFS17335); 29-VI-2011, C.A. Ribeiro \& G.J.P. Ramos s.n. (HUEFS178362, HUEFS 178364 , HUEFS178366, HUEFS178368, HUEFS178372, HUEFS178377, HUEFS178379); 19-VIII-2011, C.W.N. Moura \& G.J.P. Ramos s.n. (HUEFS185348, HUEFS 185350 , HUEF 185354 ); 9-XII-2011, C.A. Ribeiro \& G.J.P. Ramos s.n. (HUEFS185388, HUEFS 185390 , HUEFS 185392); 10-II-2012, C.A. Ribeiro \& G.J.P. Ramos S.n. (HUEFS185409, HUEFS 185410, HUEFS185411, HUEFS185415, HUEFS185417); Lençóis, Marimbus do Remanso, 30-VI-2011, C.A. Ribeiro \& G.J.P. Ramos s.n. (HUEFS178383, HUEFS178387, HUEFS178393).

Hábitat: plâncton, perifíton

Conforme Sant'Anna (1984), C. microporum é uma espécie muito bem definida dentro do gênero, devido à presença de células esféricas, diminutos espaços intercelulares e forma globosa dos cenóbios. Ainda assim, a espécie pode ser confundida com outras, principalmente com $C$. astroideum e C. pseudomicroporum. A primeira difere por apresentar células ovoides em vista lateral enquanto a segunda difere por apresentar curtos processos interligando as células. Ressalte-se aqui a importância de análises populacionais de cada uma dessas três espécies, pois quando os cenóbios são jovens as células são igualmente esféricas, dificultando a diferenciação entre essas espécies.
Coelastrum proboscideum Bohlin, in Wittrock, Nordstedt \& Lagerheim, Alg. Aq. Dulc. Exsicc. 26: p. 1240.1896.

Figura $2 \mathrm{f}$

Cenóbio tetraédrico, 4 ou 8 células unidas por 3 processos; células em vistas lateral e apical subtriangulares, face externa cônico-truncada, protoplastídios triangulares ou esféricos, espaços intercelulares poligonais; parede celular lisa, margens retas a levemente côncavas; cloroplastídio 1, parietal, 1 pirenoide. Dimensões: cenóbio 30-36,5 ㅆm diâm., célula 11,5-13,5 $\mu \mathrm{m}$ diâm.

Material examinado: BRASIL. BAHIA: Andaraí, Marimbus do Baiano, 9-XII-2011, C.A. Ribeiro \& G.J.P. Ramos s.n. (HUEFS185388).

Hábitat: perifíton.

Segundo Komárek \& Fott(1983), C. proboscideum apresenta a face externa livre truncada, enquanto que C. sphaericum apresenta a face livre arredondada, com tubérculos e espessamento polar. Além da morfologia, tais espécies são também separadas pela distribuição geográfica, uma vez que $C$. sphaericum foi referida apenas para países de clima temperado e C. proboscideum teve sua ocorrência registrada unicamente em países tropicais e subtropicais. Esse é o primeiro registro da ocorrência da espécie no Estado da Bahia.

Coelastrum pseudomicroporum Koršikov, Protococcinae: 348. 1953.

Figura $2 \mathrm{~g}$

Cenóbio esférico, 8,16 ou 32 células unidas por 5-6 processos; células ovoides a cuneiformes em vista lateral, células esféricas em vista apical, espaços intercelulares triangulares; parede celular lisa; cloroplastídio 1, parietal, 1 pirenoide. Dimensões: cenóbio 35-60 $\mu \mathrm{m}$ diâm., célula 10-14 $\mu \mathrm{m}$ diâm.

Material examinado: BRASIL. BAHIA: Lençóis, Marimbus do Remanso, 10-XII-2011, C.A. Ribeiro \& G.J.P. Ramos S.n. (HUEFS185398).

Hábitat: perifíton

Segundo Nogueira (1991), os cenóbios de C. pseudomicroporum lembram os de C. astroideum De Notaris e os de C. microporum Nägeli, diferindo de ambos pela presença de processos curtos interligando as células. Quando jovens, as células dessas espécies apresentam forma esférica exigindo, por isso, o estudo de uma amostra populacional para evitar erros de 
identificação. Nas populações ora analisadas todos os indivíduos apresentaram cinco ou seis processos, concordando com as observações de Komárek \& Fott (1983), Comas (1996) e Nogueira (1991). Esse é o primeiro registro da ocorrência da espécie no Estado da Bahia

Coelastrum pulchrum Schmidle, Ber. dt. bot. Ges. 10: 206. 1892.

Figura $2 \mathrm{~h}$

Cenóbio esférico, 16 ou 32 células unidas por 5-6 projeções; células subovoides, 1 apêndice cônicotruncado em vista lateral, células poliédricas em vista apical; espaços intercelulares triangulares a esféricos; cloroplastídio 1, parietal, 1 pirenoide. Dimensões: cenóbio 80-86 $\mu \mathrm{m}$ diâm., célula 12-18,8 $\mu \mathrm{m}$ diâm.

Material examinado: BRASIL. BAHIA: Andaraí, Marimbus do Baiano, 1-IV-2011, C.W.N. Moura \& G.J.P. Ramos s.n. (HUEFS178327, HUEFS178329; HUEFS178332); 26-X-2011, C.A. Ribeiro \& G.J.P. Ramos s.n. (HUEFS185371); 9-XII-2011, C.A. Ribeiro \& G.J.P. Ramos s.n. (HUEFS185388, HUEFS185390, HUEFS185392); 10-II-2012, C.A. Ribeiro \& G.J.P. Ramos s.n. (HUEFS185411); Lençóis, Marimbus do Remanso, 2-IV-2011, C.W.N. Moura \& G.J.P. Ramos s.n. (HUEFS178347); 10-XII-2011, C.A. Ribeiro \& G.J.P. Ramos s.n. (HUEFS185398, HUEFS185405); 11-II-2012, C.A. Ribeiro \& G.J.P. Ramos s.n. (HUEFS185427).

Hábitat: plâncton, perifíton.

Morfologicamente, Coelastrum pulchrum lembra C. indicum, no entanto, este último apresenta células esféricas e não possui apêndice cônico-truncado em vista lateral (Comas 1996). Segundo Komárek (1983), a espécie é frequentemente encontrada na zona tropical em países como Brasil, Venezuela, Paraguai e Cuba, e é raramente citada para a zona temperada. A espécie geralmente ocorre desde ambientes oligotróficos até mesotróficos (Comas 1996). Esse é o primeiro registro da ocorrência da espécie no Estado da Bahia.

Dimorphococcus lunatus A. Braun, Alg. Unicell: 44. 1855.

Figura 2 i

Cenóbio alongado, sincenóbios formados por 4-8 células com disposição alternada, unidos entre si por restos das paredes da célula-mãe na forma de fios de mucilagem; células internas cilíndricas, ovoides, elípticas; células externas reniformes a cordiformes; cloroplastídio 1, parietal, 1 pirenoide. Dimensões: célula 8,8-15 $\mu \mathrm{m}$ compr., 3,8-6,2 $\mu \mathrm{m}$ larg.

Material examinado: BRASIL. BAHIA: Andaraí, Marimbus do Baiano, 1-IV-2011, C.W.N. Moura \& G.J.P. Ramos s.n. (HUEFS178326, HUEFS178332); 29-VI-2011, C.A. Ribeiro \& G.J.P. Ramos s.n. (HUEFS178362, HUEFS178364, HUEFS178366, HUEFS178377); 9-XII-2011, C.A. Ribeiro \& G.J.P. Ramos s.n. (HUEFS185388, HUEFS185392); Lençóis, Marimbus do Remanso, 2-IV-2011, C.W.N. Moura \& G.J.P. Ramos s.n. (HUEFS178359); 30-VI-2011, C.A. Ribeiro \& G.J.P. Ramos s.n. (HUEFS178380, HUEFS178385, HUEFS178387, HUEFS178389, HUEFS178391, HUEFS178394); 20-VIII-2011, C.W.N. Moura \& G.J.P. Ramos S.n. (HUEFS185364, HUEFS185366, HUEFS185367); 27-X-2011, C.A. Ribeiro \& G.J.P. Ramos s.n. (HUEFS185380); 10-XII-2011, C.A. Ribeiro \& G.J.P. Ramos s.n. (HUEFS185398, HUEFS185399, HUEFS185401, HUEFS185403, HUEFS185404, HUEFS185405); 11-II-2012, C.A. Ribeiro \& G.J.P. Ramos s.n. (HUEFS185418, HUEFS185419, HUEFS185420, HUEFS185421, HUEFS185423, HUEFS185425, HUEFS185426, HUEFS185427).

Hábitat: plâncton, perifíton.

Durante as análises do material coletado foi possível observar variação na forma das células externas do cenóbio, desde reniformes a cordiformes, e as internas, desde ovoides até elípticas. Os exemplares examinados durante este estudo concordaram com as descrições e as ilustrações apresentadas em Comas (1996) para material de Cuba, Nogueira (1991) para material do Rio de Janeiro e Hentschke \& Torgan (2010a) para material do Rio Grande do Sul. Tsarenko \& John (2011) consideram D. lunatus uma espécie bioindicadora de ambiente oligotrófico.

\section{Subfamília Scenedesmoidea}

Comasiella arcuata (Lemmermann) E. Hegewald, M. Wolf, Al. Keller, Friedl \& Krienitz var. platydisca (G.M. Smith) E. Hegewald \& M. Wolf, Phycologia 49: 332. 2010.

Figuras 2 j-1

Cenóbio plano formado por 4-8 células dispostas em série dupla, alternada, no mesmo plano, com ou sem espaços intercelulares, envoltas em bainha de mucilagem inconspícua; células reniformes, polos 
arredondados, células externas não totalmente alinhadas; cloroplastídio 1, parietal, 1 pirenoide. Dimensões: célula 5,5-9,0 $\mu \mathrm{m}$ compr., 2,5-3,5 $\mu \mathrm{m}$ larg.

Material examinado: BRASIL. BAHIA: Andaraí, Marimbus do Baiano, 1-IV-2011, C.W.N. Moura \& G.J.P. Ramos s.n. (HUEFS178326, HUEFS178327; HUEFS178329, HUEFS178332, HUEFS178335); 29-VI-2011, C.A. Ribeiro \& G.J.P. Ramos s.n. (HUEFS178362, HUEFS178364, HUEFS178366, HUEFS178374, HUEFS178377); 19-VIII-2011, C.W.N. Moura \& G.J.P. Ramos s.n. (HUEFS185350, HUEFS185355); 26-X-2011, C.A. Ribeiro \& G.J.P. Ramos s.n. (HUEFS185369, HUEFS 185371 , HUEFS185374, HUEFS185376, HUEFS185377); 9-XII-2011, C.A. Ribeiro \& G.J.P. Ramos s.n. (HUEFS185403); 10-II-2012, C.A. Ribeiro \& G.J.P. Ramos s.n. (HUEFS185412, HUEFS185414, HUEFS185415, HUEFS185416); Lençóis, Marimbus do Remanso, 2-IV-2011, C.W.N. Moura \& G.J.P. Ramos s.n. (HUEFS178352, HUEFS178361); 20-VIII-2011, C.W.N. Moura \& G.J.P. Ramos s.n. (HUEFS185364, HUEFS185367).

Hábitat: plâncton, perifíton.

O gênero Comasiella foi proposto Hegewald et al. (2010) baseado, principalmente, em dados moleculares (ITS2). Comasiella arcuata var. platydisca difere da variedade típica da espécie por apresentar as células dispostas em um único plano (Hegewald \& Silva 1988, Hegewald \& Wolf 2003, como Scenedesmus arcuatus var. platydiscus). Os exemplares analisados concordam com a descrição, medidas e ilustrações apresentadas por Souza \& Felisberto (2014) para o material de Goiás, Domingues \& Torgan (2012) para o Rio Grande do Sul e Godinho et al. (2010) para São Paulo (identificada como Scenedesmus arcuatus var. platydiscus). Esse é o primeiro registro da ocorrência da variedade no Estado da Bahia.

Chave artificial para identificação das morfoespécies de Scenedesmus registradas no Pantanal dos Marimbus.

1. Cenóbios com uma fileira de células, arranjo linear

1. Cenóbios com duas fileiras de células, arranjo

alternado . S. obtusus

2. Células externas e internas retas

2. Células externas convexas e internas retas S. acunae 3. Parede celular com espessamento ... S. ellipticus 3. Parede celular sem espessamento .... S. ecornis
Scenedesmus acunae Comas, Acta Botánica Cubana 2: 7-8, fig. 7d-f. 1980.

Figura 3 a

Cenóbio plano, linear, 4 células; células elipsoides a oblongas, polos arredondados; células externas convexas, células internas retas, ambas podendo apresentar espessamento na parede celular; cloroplastídio 1, parietal, 1 pirenoide. Dimensões: célula 7,5-16 $\mu \mathrm{m}$ compr., 3,8-5 $\mu \mathrm{m}$ larg.

Material examinado: BRASIL. BAHIA: Andaraí, Marimbus do Baiano, 1-IV-2011, C.W.N. Moura \& G.J.P. Ramos s.n. (HUEFS178326, HUEFS178327, HUEFS178329, HUEFS178332, HUEFS178344); 29-VI-2011, C.A. Ribeiro \& G.J.P. Ramos s.n. (HUEFS178362, HUEFS178366, HUEFS178372, HUEFS178374, HUEFS 178379); 19-VIII-2011, C.W.N. Moura \& G.J.P. Ramos s.n. (HUEFS185348); 26-X-2011, C.A. Ribeiro \& G.J.P. Ramos s.n. (HUEFS185368, HUEFS185374, HUEFS185377); 9-XII-2011, C.A. Ribeiro \& G.J.P. Ramos s.n. (HUEFS185388); Lençóis, Marimbus do Remanso, 2-IV-2011, C.W.N. Moura \& G.J.P. Ramos s.n. (HUEFS178359); 30-VI-2011, C.A. Ribeiro \& G.J.P. Ramos s.n. (HUEFS178383, HUEFS178389, HUEFS178393, HUEFS178394); 27-X-2011, C.A. Ribeiro \& G.J.P. Ramos s.n. (HUEFS185380); 11-II-2012, C.A. Ribeiro \& G.J.P. Ramos s.n. (HUEFS185408, HUEFS185410, HUEFS185416, HUEFS185418).

Hábitat: perifíton.

Morfologicamente, Scenedesmus acunae é próximo de S. ecornis (Ralfs) Chodat e S. ellipticus Corda. Segundo Godinho et al. (2010), essas espécies são de difícil separação devido à ocorrência de morfotipos muito semelhantes. Contudo, S. ecornis difere de $S$. acunae por possuir células relativamente mais elípticas, células externas retas e parede celular sem espessamento, ao passo que $S$. ellipticus difere por apresentar células elípticas, com espessamento na parede. Este é o primeiro registro da ocorrência da espécie no Estado da Bahia.

Scenedesmus ecornis (Ehrenberg) Chodat, Zeitschrift für Hydrologie 3: 170. 1926.

Figura $3 \mathrm{~b}$

Cenóbios planos, lineares, 2-4 células; células elípticas, retas, arredondados, parede celular lisa, sem espessamentos; cloroplastídio 1, parietal, 1 pirenoide. Dimensões: célula 8,5-16 $\mu \mathrm{m}$ compr., 3,5-6,5 $\mu \mathrm{m}$ larg. 
Material examinado: BRASIL. BAHIA: Andaraí, Marimbus do Baiano, 1-IV-2011, C.W.N. Moura \& G.J.P. Ramos s.n. (HUEFS178326, HUEFS178327, HUEFS 178329, HUEFS178332, HUEFS178335, HUEFS 178341, HUEFS178342); 29-VI-2011, C.A. Ribeiro \& G.J.P. Ramos s.n. (HUEFS178362, HUEFS 178364, HUEFS178366, HUEFS178372, HUEFS178374); 19-VIII-2011, C.W.N. Moura \& G.J.P. Ramos s.n. (HUEFS185351, HUEFS185357); 26-X-2011, C.A. Ribeiro \& G.J.P. Ramos s.n. (HUEFS185368, HUEFS185369, HUEFS185371, HUEFS185375); 9-XII-2011, C.A. Ribeiro \& G.J.P. Ramos s.n. (HUEFS185388, HUEFS185390, HUEFS 185393 , HUEF 185396 ); 10-II-2012, C.A. Ribeiro \& G.J.P. Ramos s.n. (HUEFS185409, HUEFS185411, HUEFS185412, HUEFS185415, HUEFS18541); Lençóis, Marimbus do Remanso, 2-IV-2011, C.W.N. Moura \& G.J.P. Ramos s.n. (HUEFS178347); 30-VI-2011, C.A. Ribeiro \& G.J.P. Ramos s.n. (HUEFS178391); 20-VIII-2011, C.W.N. Moura \& G.J.P. Ramos s.n. (HUEFS185359, HUEFS 185364, HUEFS185365, HUEFS185366, HUEFS185367); 27-X-2011, C.A. Ribeiro \& G.J.P. Ramos s.n. (HUEFS185381, HUEFS 185384 , HUEFS 185385, HUEFS 185386); 10-XII-2011, C.A. Ribeiro \& G.J.P. Ramos S.n. (HUEFS185398, HUEFS185399, HUEFS185400, HUEFS185401, HUEFS185402, HUEFS185405, HUEFS185406, HUEFS185407); 11-II-2012, C.A. Ribeiro \& G.J.P. Ramos s.n. (HUEFS185421, HUEFS 1854122 , HUEFS185423, HUEFS185425, HUEFS185426, HUEFS185427).

Hábitat: perifíton.

Scenedesmus ecornis é próximo de S. ellipticus, contudo, este difere por apresentar células com espessamento na parede celular. A morfologia dos exemplares estudados está de acordo com os referidos por Komárek \& Fott (1983), Comas (1996) para Cuba e Ferragut et al. (2005) para São Paulo.

Scenedesmus ellipticus Corda, Almanach de Carlsbad 5: 208, pl. 4, fig. 48-49. 1835

Figura $3 \mathrm{c}$

Cenóbio plano, linear, 4 ou 8 células; células elípticas a oblongas, retas, polos arredondados, células externas e internas com espessamento na parede celular; cloroplastídio 1, parietal, 1 pirenoide. Dimensões: célula 13,5-16,5 $\mu \mathrm{m}$ compr., 5-6,5 $\mu \mathrm{m}$ larg.
Material examinado: BRASIL. BAHIA: Andaraí, Marimbus do Baiano, 29-VI-2011, C.A. Ribeiro \& G.J.P. Ramos s.n. (HUEFS185368, HUEFS178379); Lençóis, Marimbus do Remanso, 2-IV-2011, C.W.N. Moura \& G.J.P. Ramos s.n. (HUEFS178352, HUEFS178358).

Hábitat: perifíton.

Conforme Tsarenko \& John (2011), S. ellipticus pode apresentar células arranjadas alternadamente no cenóbio, uma mais para cima e outra mais para baixo e, raramente, apresentar células curvadas. Nogueira (1991) estudou populações coletadas no município do Rio de Janeiro e encontrou alguns cenóbios envoltos por mucilagem. Nos exemplares atualmente estudados não foram observadas essas características, mantendo-se sempre o padrão de cenóbios lineares sem mucilagem. Esse é o primeiro registro da presença da espécie no Estado da Bahia.

Scenedesmus obtusus Meyen, Verh. K. Leopold.Carol. Akad. Naturf., 14: 775, pl. 43, fig. 30-31. 1829.

Figuras 3 d-e

Cenóbio plano, alternado, 4 ou 8 células; células ovado-cilíndricas, polos arredondados; células externas geralmente oblíquas, células internas retas; parede celular levemente espessada; cloroplastídio 1, parietal, 1 pirenoide. Dimensões: célula 7,5-15 $\mu \mathrm{m}$ compr., 5-7,5 $\mu \mathrm{m}$ larg.

Material examinado: BRASIL. BAHIA: Andaraí, Marimbus do Baiano, 1-IV-2011, C.W.N. Moura \& G.J.P. Ramos s.n. (HUEFS178326, HUEFS178327, HUEFS178329, HUEFS178332, HUEFS178335, HUEFS178344); 29-VI-2011, C.A. Ribeiro \& G.J.P. Ramos s.n. (HUEFS178362, HUEFS178372, HUEFS178377, HUEFS178379); 26-X-2011, C.A. Ribeiro \& G.J.P. Ramos s.n. (HUEFS185377); 9-XII-2011, C.A. Ribeiro \& G.J.P. Ramos s.n. (HUEFS185388, HUEFS185392); Lençóis, Marimbus do Remanso, 30-VI-2011, C.A. Ribeiro \& G.J.P. Ramos s.n. (HUEFS178383, HUEFS178385, HUEFS178387, HUEFS178389, HUEFS178393); 20-VIII-2011, C.W.N. Moura \& G.J.P. Ramos s.n. (HUEFS185361, HUEFS185363, HUEFS185365); 27-X-2011, C.A. Ribeiro \& G.J.P. Ramos s.n. (HUEFS185379, HUEFS185380, HUEFS185381, HUEFS185384, HUEFS185385, HUEFS185386, HUEFS185387); 10-XII-2011, C.A. Ribeiro \& G.J.P. Ramos s.n. (HUEFS185401, HUEFS185403, 
HUEFS185404); 11-II-2012, C.A. Ribeiro \& G.J.P. Ramos s.n. (HUEFS 185418 , HUEFS 185423 , HUEFS 185424, HUEFS185425, HUEFS185426, HUEFS185427).

Hábitat: perifíton.

Segundo Bortolini et al. (2010b), S. obtusus pode ser facilmente confundido com $S$. ovalternus Chodat e com Comasiella arcuata (Lemmermann) E. Hegewald et al. Entretanto, a primeira é distinta por possuir espaços intercelulares menores e pelas células mais fusiformes, e a segunda, pelas células reniformes. No Pantanal dos Marimbus, observou-se predominância de cenóbios com oito células, as quais mostraram pouca variação morfológica, conservando a forma ovado-cilíndrica com parede celular levemente espessada. Este é o primeiro registro da ocorrência da espécie para o Estado da Bahia.

Verrucodesmus verrucosus (Y.V. Roll) E. Hegewald, Fottea 14(2): 149-164. 2013.

Figuras 3 f-g

Cenóbio plano, às vezes em planos distintos, 4 ou 8 células dispostas em série dupla; células elipsoides; parede celular com granulações; cloroplastídio 1, parietal, 1 pirenoide. Dimensões: célula 9-13,5 $\mu \mathrm{m}$ compr., 5-6,5 $\mu \mathrm{m}$ larg.

Material examinado: BRASIL. BAHIA: Andaraí, Marimbus do Baiano, 1-IV-2011, C.W.N. Moura \&

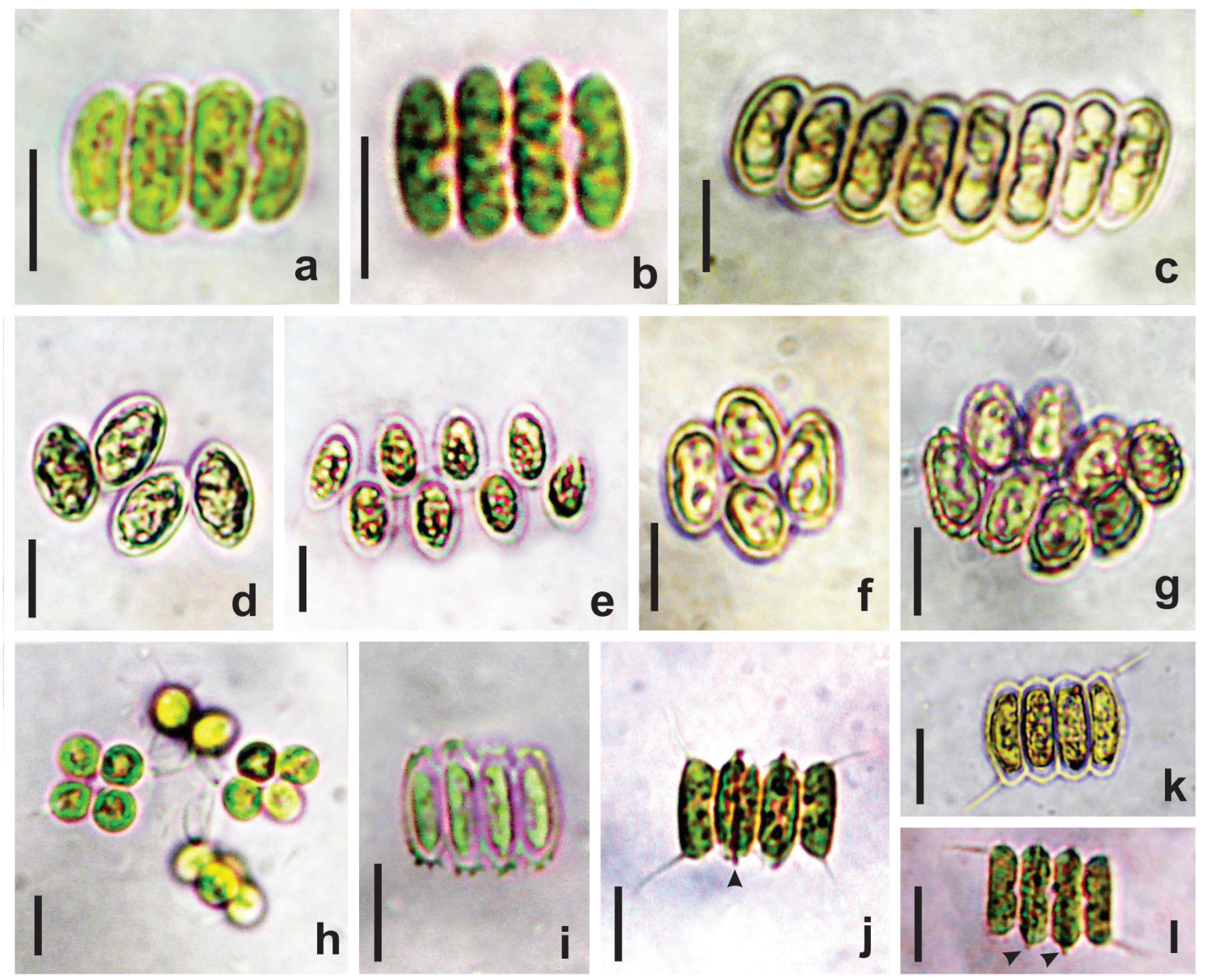

Figura 3 a. Scenedesmus acunae. b. S. ecornis. c. S. ellipticus. d-e. S. obtusus. f-g. Verrucodesmus verrucosus. h. Westella botryoides. i. Desmodesmus aculeolatus. j. D. armatus var. armatus. k-1. D. armatus var. bicaudatus. Barras $=10 \mu \mathrm{m}$ (setas: detalhe das costelas).

Figure 3 a. Scenedesmus acunae. b. S. ecornis. c. S. ellipticus. d-e. S. obtusus. f-g. Verrucodesmus verrucosus. h. Westella botryoides. i. Desmodesmus aculeolatus. j. D. armatus var. armatus. k-1. D. armatus var. bicaudatus. Bars $=10 \mu$ m (arrows: detail of the ribs). 
G.J.P. Ramos s.n. (HUEFS178332, HUEFS178342); 29-VI-2011, C.A. Ribeiro \& G.J.P. Ramos s.n. (HUEFS178372, HUEFS178374); 19-VIII-2011, C.W.N. Moura \& G.J.P. Ramos s.n. (HUEFS185348); 9-XII-2011, C.A. Ribeiro \& G.J.P. Ramos s.n. (HUEFS185388, HUEFS185392, HUEFS185393, HUEFS185396); 10-II-2012, C.A. Ribeiro \& G.J.P. Ramos s.n. (HUEFS185409, HUEFS185414); Lençóis, Marimbus do Remanso, 2-IV-2011, C.W.N. Moura \& G.J.P. Ramos s.n. (HUEFS178352); 30-VI-2011, C.A. Ribeiro \& G.J.P. Ramos s.n. (HUEFS178385, HUEFS178387); 10-XII-2011, C.A. Ribeiro \& G.J.P. Ramos s.n. (HUEFS185403); 11-II-2012, C.A. Ribeiro \& G.J.P. Ramos s.n. (HUEFS185425).

Hábitat: perifíton.

O gênero Verrucodesmus, proposto recentemente por Hegewald et al. (2013), fazia parte de Scenedesmus sensu lato e sua separação foi suportada por dados moleculares (Verrucosdesmus apresenta mais de 100 bases nucleotídicas de diferença em relação à Scenedesmus), e morfológicos, como a granulação da parede celular, que na verdade é uma excreção da mesma, característica diacrítica de Verrucodesmus (Hegewald et al. 2013). A principal característica de $V$. verrucosus é o arranjo das células em duas séries e a existência de granulações ao longo da parede celular. Devido a esse arranjo, a espécie pode ser confundida com Comasiella arcuata var. platydisca, contudo, esta é diferente por apresentar parede celular lisa e células reniformes.

No Pantanal dos Marimbus, observou-se cenóbios de $V$. verrucosus com 4 ou 8 células, sendo o último mais comum. Foi constatada também variação na granulação da parede celular, a qual foi visível geralmente na margem das células (cenóbios jovens, com quatro células) ou ao longo de toda parede celular (cenóbios adultos, com oito células). Embora a maioria da literatura descreva esse táxon apresentando cenóbios planos, no presente estudo constatou-se a disposição das células externas em planos distintos, concordando com as observações de Sant'Anna (1984) e Comas (1996). Isto é devido, provavelmente, ao fato das células serem fortemente compactadas, aparecendo angulares pela compressão mutua (Sant'Anna 1984). Esse é o primeiro registro do gênero para o Estado da Bahia.

Westella botryoides (West) De Wildemann, Bull. Herb. Boissier 5: 532. 1897.

Figura $3 \mathrm{~h}$

Cenóbio com 4 células dispostas de modo cruciado, formando sincenóbios com 8 ou 16 células unidas pelo resto da parede celular materna através de fios de mucilagem; células globosas à subtriangulares; cloroplastídio 1, parietal, 1 pirenoide. Dimensões: célula 3,8-6 $\mu \mathrm{m}$ diâm.

Material examinado: BRASIL. BAhIA: Andaraí, Marimbus do Baiano, 1-IV-2011, C.W.N. Moura \& G.J.P. Ramos s.n. (HUEFS178327, HUEFS178329, HUEFS 178332, HUEFS178335); 29-VI-2011, C.A. Ribeiro \& G.J.P. Ramos s.n. (HUEFS178362, HUEFS178364, HUEFS178366, HUEFS178368, HUEFS178371, HUEFS178372, HUEFS178374, HUEFS178377, HUEFS178379); 19-VIII-2011, C.W.N. Moura \& G.J.P. Ramos s.n. (HUEFS185348); 26-X-2011, C.A. Ribeiro \& G.J.P. Ramos s.n. (HUEFS185368, HUEFS185376); 9-XII-2011, C.A. Ribeiro \& G.J.P. Ramos s.n. (HUEFS185388, HUEFS185390, HUEFS185391, HUEFS185392, HUEFS185395, HUEFS185396, HUEFS185397); 10-II-2012, C.A. Ribeiro \& G.J.P. Ramos s.n. (HUEFS185408, HUEFS185409, HUEFS185412, HUEFS185413, HUEFS185414, HUEFS185415, HUEFS185416); Lençóis, Marimbus do Remanso, 2-IV-2011, C.W.N. Moura \& G.J.P. Ramos s.n. (HUEFS178350, HUEFS178352, HUEFS178359); 30-VI-2011, C.A. Ribeiro \& G.J.P. Ramos s.n. (HUEFS178385, HUEFS178391); 20-VIII-2011, C.W.N. Moura \& G.J.P. Ramos s.n. (HUEFS185359, HUEFS185360, HUEFS185365, HUEFS185367); 27-X-2011, C.A. Ribeiro \& G.J.P. Ramos s.n. (HUEFS185379, HUEFS185380, HUEFS185381, HUEFS185383, HUEFS185384, HUEFS185385, HUEFS185386, HUEFS 185387); 10-XII-2011, C.A. Ribeiro \& G.J.P. Ramos s.n. (HUEFS185401, HUEFS185402, HUEFS185404); 11-II-2012, C.A. Ribeiro \& G.J.P. Ramos s.n. (HUEFS185419, HUEFS185420, HUEFS185423).

Hábitat: plâncton, perifíton.

Segundo Sant'Anna (1984), Westella botryoides é morfologicamente próxima a Dictyosphaerium puchellum H.C. Woodard. (= Mucidosphaerium puchellum (H.C.Woodard) C.Bock), entretanto, a última espécie é diferente por apresentar fios de mucilagem ramificados dicotomicamente. De acordo com Comas (1996), W. botryoides é cosmopolita e geralmente encontrada em ambientes eutróficos. Considerando o conjunto das características diagnósticas de $W$. botryoides, as populações ora examinadas concordam com as descrições, ilustrações e medidas apresentadas por Martins et al. (1991) para material do Dique do Tororó, Salvador. 
Subfamília Desmodesmoideae

Chave artificial para identificação das morfoespécies de Desmodesmus registradas no Pantanal dos Marimbus

1. Células com espinhos longos

2. Células externas com 1 único espinho, localizadoapenasemum dos polos; espinhos do cenóbio diagonalmente opostos com arranjo bicaudato .... D. armatus var. bicaudatus

2. Células externas com 2 espinhos, 1 em cada polo; espinhos do cenóbio com arranjo quadricaudato

3. Células internas e externas elíptico-fusiformes .... D. opoliensis var. mononensis

3. Células internas e externas elípticas, oblongas ou trapeziformes

4. Células com a presença de costelas D. armatus var. armatus

4. Células sem a presença de costelas .. D. communis

1. Células com espinhos curtos ou grânulos

5. Células com parede celular ornamentada com grânulos

6. Células com 1 espinho convexo em cada polo ... D. arthrodesmiformis

6. Células sem espinhos ................ D. granulatus

5. Células com parede celular lisa ou ornamentada com costelas

7. Células com apenas 1 espinho polar curto, margens das células externas geralmente serrilhadas . D. serratus

7. Células com 1-2(-3) dentículos polares, margens das células externas geralmente lisas

9. Células com a presença de costelas D. brasiliensis

9. Células sem a presença de costelas D. aculeolatus

Desmodesmus aculeolatus (Reinsch) P.M. Tsarenko, Cryptogamie: Algologie 10(4): 183. 2000.

Figura 3 i

Cenóbio plano, 4 células dispostas linearmente; células internas cilíndricas a oval-fusiformes, células externas oblongas com margem externa côncava ou reta, polos levemente arredondados à truncados, 1-2(-3) dentículos polares, às vezes formando 1 coroa apical; parede celular lisa; cloroplastídio 1, parietal,
1 pirenoide. Dimensões: célula 8,5-11 $\mu \mathrm{m}$ compr., 2,5-3,5 $\mu \mathrm{m}$ larg., dentículo 0,8-1,2 $\mu \mathrm{m}$ compr.

Material examinado: BRASIL. BAHIA: Andaraí, Marimbus do Baiano, 1-IV-2011, C.W.N. Moura \& G.J.P. Ramos s.n. (HUEFS178335, HUEFS178336); 29-VI-2011, C.A. Ribeiro \& G.J.P. Ramos s.n. (HUEFS178374, HUEFS178379); 19-VIII-2011, C.W.N. Moura \& G.J.P. Ramos s.n., (HUEFS185354); 26-X-2011, C.A. Ribeiro \& G.J.P. Ramos s.n. (HUEFS 185368, HUEFS 185374); 9-XII-2011, C.A. Ribeiro \& G.J.P. Ramos s.n. (HUEFS185393); 10-II-2012, C.A. Ribeiro \& G.J.P. Ramos s.n. (HUEFS185408, HUEFS185409, HUEFS185412, HUEFS185413, HUEFS185414, HUEFS185415, HUEFS185416); Lençóis, Marimbus do Remanso, 30-VI-2011, C.A. Ribeiro \& G.J.P. Ramos s.n. (HUEFS178385, HUEFS178390, HUEFS178393); 20-VIII-2011, C.W.N. Moura \& G.J.P. Ramos s.n. (HUEFS185364, HUEFS185366, HUEFS185367); 27-X-2011, C.A. Ribeiro \& G.J.P. Ramos s.n. (HUEFS185378, HUEFS185379, HUEFS185386, HUEFS185387); 10-XII-2011, C.A. Ribeiro \& G.J.P. Ramos s.n. (HUEFS185400, HUEFS185401, HUEFS185402, HUEFS185403, HUEFS185404, HUEFS185405, HUEFS185407); 11-II-2012, C.A. Ribeiro \& G.J.P. Ramos s.n. (HUEFS185418, HUEFS185419, HUEFS185420, HUEFS185421, HUEFS185423, HUEFS185424, HUEFS185425, HUEFS185426, HUEFS185427).

Hábitat: plâncton, perifíton.

Hindák (1990: pl. 39, figs. 1-4) ilustrou variação morfológica em Scenedesmus aculeolatus Reinsch (=D. aculeolatus), enfatizando sua plasticidade fenotípica, principalmente em relação às células externas, que ora apareceram com margem externa côncava, ora reta e até irregular, bem como o número de dentículos que variou de um a três. Tais informações concordam com o que observamos nos espécimes dos Marimbus. Esse é o primeiro registro da espécie no Estado da Bahia.

Desmodesmus armatus (Chodat) E. Hegewald var. armatus, Algological Studies 96: 2. 2000.

Figura $3 \mathrm{j}$

Cenóbio plano, linear, 4 células; células internas elípticas, polos arredondados a fusiformes, células externas trapeziformes com 1 longo espinho em cada polo; parede celular ornamentada com costelas longitudinais medianas; cloroplastídio 1, parietal, 
1 pirenoide. Dimensões: célula 11-16,2 $\mu \mathrm{m}$ compr., 3,5-5 $\mu \mathrm{m}$ larg., espinho 7,5-10 $\mu \mathrm{m}$ compr.

Material examinado: BRASIL. BAHIA: Andaraí, Marimbus do Baiano, 9-XII-2011, C.A. Ribeiro \& G.J.P. Ramos S.n. (HUEFS185388); Lençóis, Marimbus do Remanso, 11-II-2012, C.A. Ribeiro \& G.J.P. Ramos s.n. (HUEFS185419, HUEFS185422, HUEFS185423, HUEFS185426).

Hábitat: perifíton.

Quanto à morfologia dos espécimes, D. armatus assemelha-se muito a $D$. communis (E. Hegewald) E. Hegewald, entretanto, este último é distinto por não possuir costelas. De acordo com Hindák (1990), D. armatus var. armatus é uma das espécies em que os caracteres diagnósticos apresentam ampla plasticidade fenotípica. Nos espécimes do Pantanal dos Marimbus constatou-se variação na forma das costelas, que ora se apresentaram inteiras, ora fragmentadas. Tsarenko \& John (2011) consideram a espécie cosmopolita, sendo encontrada, em geral, no plâncton de ambientes mesotróficos. Esse é o primeiro registro da espécie no Estado da Bahia.

Desmodesmus armatus (Chodat) E. Hegewald var. bicaudatus (Guglielmetti) E. Hegewald, Algological Studies 96: 4. 2000.

Figura 3 k-1

Cenóbio plano, 4 células dispostas linearmente; células oblongas à hexagonais; células internas com margens retas, sem espinhos, células externas com 1 único espinho, localizado em um dos polos, espinhos do cenóbio diagonalmente opostos; parede celular ornamentada com costelas contínuas ou fragmentadas; cloroplastídio 1, parietal, 1 pirenoide. Dimensões: célula 12,5-15 $\mu \mathrm{m}$ compr., 3,5-5 $\mu \mathrm{m}$ larg., espinho 3,5-6 $\mu \mathrm{m}$ compr.

Material examinado: BRASIL. BAHIA: Andaraí, Marimbus do Baiano, 29-VI-2011, C.A. Ribeiro \& G.J.P. Ramos s.n. (HUEFS178362, HUEFS178374); 9-XII-2011, C.A. Ribeiro \& G.J.P. Ramos s.n. (HUEFS185388).

Hábitat: perifíton.

Desmodesmus armatus var. bicaudatus difere da variedade típica da espécie pelo seu caráter bicaudado. Segundo Godinho et al. (2010), a morfologia celular é bastante variável nesta espécie, principalmente no que tange às células externas do cenóbio que, em alguns espécimes, são elípticas, porém, com os polos aproximadamente truncados. Ainda segundo os referidos autores, a espécie pode apresentar a margem das células externas serrilhada, mas, essa característica não foi observada nos espécimes do Pantanal dos Marimbus.

O detalhe das costelas foi uma característica que também variou nos exemplares ora estudados, entretanto, elas estiveram presentes mesmo que, às vezes, de difícil visualização e de forma fragmentada, conforme também foi observado por Nogueira (1991) em exemplares do Rio de Janeiro. Constatou-se, ainda, uma plasticidade fenotípica nas células do cenóbio, as quais variaram desde oblongas até hexagonais (menos comum), fato este também constatado por Moresco \& Bueno (2007). Esse é o primeiro registro da espécie no Estado da Bahia.

Desmodesmus arthrodesmiformis (Schröder) S.S.

An, Friedl \& E. Hegewald In Hegewald, Algological Studies 96: 7. 2000.

Figura $4 \mathrm{a}-\mathrm{b}$

Cenóbio plano, 4 células dispostas linearmente; células elípticas a elíptico-fusiformes, polos levemente arredondados, convergentes, até truncados; células externas e internas com 1 espinho convexo voltado para o interior do cenóbio; parede celular granulada; cloroplastídio 1, parietal, 1 pirenoide. Dimensões: célula (7-)9-12,5 $\mu \mathrm{m}$ compr., 2,5-3,75 $\mu \mathrm{m}$ larg., espinho 1,5-2 $\mu \mathrm{m}$ compr.

Material examinado: BRASIL. BAHIA: Andaraí, Marimbus do Baiano, 26-X-2011, C.A. Ribeiro \& G.J.P. Ramos s.n. (HUEFS185376); 9-XII-2011, C.A. Ribeiro \& G.J.P. Ramos s.n. (HUEFS185388); Lençóis, Marimbus do Remanso, 11-II-2012, C.A. Ribeiro \& G.J.P. Ramos s.n. (HUEFS185425).

Hábitat: perifíton.

A principal característica de D. arthrodesmiformis é a disposição dos espinhos convexos voltados para o interior do cenóbio. Morfologicamente, esta espécie é próxima de $D$. denticulatus (Lagerheim) S.S. An. et al., contudo a última difere por apresentar os espinhos projetados para fora do cenóbio, o qual apresenta geralmente arranjo alternado. Nos espécimes analisados observou-se polimorfismo principalmente nos polos das células, que variaram desde levemente arredondados, até truncados. Segundo Tsarenko \& John (2011), os cenóbios desta espécie são encontrados, em geral, formados por duas células, raramente por quatro. Entretanto, no Pantanal 
dos Marimbus todos os espécimes analisados foram representados por cenóbios de quatro células. Esse é o primeiro registro da espécie no Estado da Bahia.

Desmodesmus brasiliensis (Bohlin) E. Hegewald, Algological Studies 96: 7. 2000.

Figura $4 \mathrm{c}$

Cenóbio plano, 4 células dispostas linearmente; células externas e internas elípticas a oblongas, polos arredondados, 1-2(-3) dentículos polares que podem ou não aparecer em todas as células do cenóbio; parede celular ornamentada com costelas longitudinais medianas ao longo de toda extensão da célula ou de forma fragmentada; cloroplastídio 1, parietal, 1 pirenoide. Dimensões: célula 18,5-23,5 $\mu \mathrm{m}$ compr., 5-7,5 $\mu \mathrm{m}$ larg., espinho 1,3-1,6 $\mu \mathrm{m}$ compr.

Material examinado: BRASIL. BAHIA: Andaraí, Marimbus do Baiano, 1-IV-2011, C.W.N. Moura \& G.J.P. Ramos s.n. (HUEFS178326, HUEFS178327, HUEFS178329, HUEFS178332, HUEFS178341, HUEFS178342, HUEFS178344, HUEFS178345); 29-VI-2011, C.A. Ribeiro \& G.J.P. Ramos s.n. (HUEFS178366, HUEFS178374); 19-VIII-2011, C.W.N. Moura \& G.J.P. Ramos s.n. (HUEFS185353); 26-X-2011, C.A. Ribeiro \& G.J.P. Ramos s.n. (HUEFS185368, HUEFS185371, HUEFS185375, HUEFS185377); 9-XII-2011, C.A. Ribeiro \& G.J.P. Ramos s.n. (HUEFS 185388, HUEFS185393); 10-II-2012, C.A. Ribeiro \& G.J.P. Ramos s.n. (HUEFS185413, HUEFS185416); Lençóis, Marimbus do Remanso, 2-IV-2011, C.W.N. Moura \& G.J.P. Ramos s.n. (HUEFS178352, HUEFS178361); 30-VI-2011, C.A. Ribeiro \& G.J.P. Ramos s.n. (HUEFS178380, HUEFS178387, HUEFS178393, HUEFS178394); 20-VIII-2011, C.W.N. Moura \& G.J.P. Ramos s.n. (HUEFS185366); 27-X-2011, C.A. Ribeiro \& G.J.P. Ramos S.n. (HUEFS185384, HUEFS185386); 10-XII-2011, C.A. Ribeiro \& G.J.P. Ramos s.n. (HUEFS185403); 11-II-2012, C.A. Ribeiro \& G.J.P. Ramos s.n. (HUEFS185421, HUEFS185421, HUEFS185424, HUEFS185425, HUEFS185426).

Hábitat: plâncton, perifíton.

Nos espécimes do Pantanal dos Marimbus foi possível constatar uma considerável plasticidade fenotípica, principalmente em relação à margem das células externas do cenóbio que ora se apresentaram ligeiramente convexas, ora retas, e ao número de espinhos polares que variou de um a três, concordando com as observações de Godinho et al. (2010).
Desmodesmus communis (E. Hegewald) E. Hegewald, Algological Studies 96: 8. 2000.

Figura 4 d-e

Cenóbio plano, 4 células dispostas linearmente; células internas oblongas, polos arredondados, células externas oblongas a trapeziformes, 1 espinho longo em cada polo, espinhos do cenóbio com arranjo quadricaudato; parede celular lisa, sem costelas; cloroplastídio 1, parietal, 1 pirenoide. Dimensões: célula 12-18,8 $\mu \mathrm{m}$ compr., 2,5-6,5 $\mu \mathrm{m}$ larg., espinho 10-17 $\mu \mathrm{m}$ compr.

Material examinado: BRASIL. BAHIA: Andaraí, Marimbus do Baiano, 10-II-2012, C.A. Ribeiro \& G.J.P. Ramos s.n. (HUEFS185408); Lençóis, Marimbus do Remanso, 20-VIII-2011, C.W.N. Moura \& G.J.P. Ramos s.n. (HUEFS185358, HUEFS185359); 27-X-2011, C.A. Ribeiro \& G.J.P. Ramos s.n. (HUEFS185381); 10-XII-2011, C.A. Ribeiro \& G.J.P. Ramos s.n. (HUEFS185400, HUEFS185403); 11-II-2012, C.A. Ribeiro \& G.J.P. Ramos s.n. (HUEFS 185420 , HUEFS 185423 , HUEFS185425, HUEFS185426).

Hábitat: perifíton.

Morfologicamente, Desmodesmus communis é próxima de $D$. maximus (West \& G.S. West) E. Hegewald, contudo, esta última difere por apresentar maiores dimensões celulares.

Desmodesmus granulatus (West \& West) Hentschke \& Torgan, Rodriguésia 61: 589. 2010.

Figura $4 \mathrm{f}$

Cenóbio plano, 4 células dispostas linearmente; células internas e externas trapeziformes a oblongas, polos truncados; parede celular ornamentada com grânulos; cloroplastídio 1, parietal, 1 pirenoide. Dimensões: célula 8,5-12 $\mu \mathrm{m}$ compr., 2-3 $\mu \mathrm{m}$ larg.

Material examinado: BRASIL. BAHIA: Andaraí, Marimbus do Baiano, 9-XII-2011, C.A. Ribeiro \& G.J.P. Ramos s.n. (HUEFS185388, HUEFS185392); Lençóis, Marimbus do Remanso, 10-XII-2011, C.A. Ribeiro \& G.J.P. Ramos s.n. (HUEFS185403); 11-II-2012, C.A. Ribeiro \& G.J.P. Ramos s.n. (HUEFS185423).

Hábitat: perifíton.

Desmodesmus granulatus aproxima-se, quanto à sua morfologia, de D. lunatus (West \& G.S.West) E. Hegewald, porém, este último é diferente por possuir 
três dentes nos polos, além da morfologia distinta das células externas, que são reniformes enquanto que as internas são elipsoides.

O material coletado no Pantanal dos Marimbus concorda com as descrições, medidas e ilustrações apresentadas por Hentschke \& Torgan (2010b) para exemplares da planície costeira do Rio Grande do Sul e Tsarenko \& John (2011) para espécimes das Ilhas Britânicas. Esse é o primeiro registro da espécie no Estado da Bahia.

Desmodesmus opoliensis (P.G. Richter) E. Hegewald var. mononensis (Chodat) E. Hegewald, Algological Studies 96: 15. 2000.

\section{Figura $4 \mathrm{~g}$}

Cenóbio plano, 4 células dispostas linearmente; células fusiformes a elipsoides; células externas com polos levemente truncados, 1 espinho longo em cada polo, parede celular lisa; cloroplastídio 1, parietal, 1 pirenoide. Dimensões: célula 13,5-16,5 $\mu \mathrm{m}$ compr., 3,5-5 $\mu \mathrm{m}$ larg., espinhos 12,5-15 $\mu \mathrm{m}$ compr.

Material examinado: BRASIL. BAHIA: Andaraí, Marimbus do Baiano, 1-IV-2011, C.W.N. Moura \& G.J.P. Ramos s.n. (HUEFS178344); Lençóis, Marimbus do Remanso, 10-XII-2011, C.A. Ribeiro \& G.J.P. Ramos s.n. (HUEFS185403).

Hábitat: perifíton.

Segundo Hegewald \& Silva (1988), D. opoliensis var. mononensis difere da variedade típica da espécie pelas células que se tocam em quase toda sua extensão e pelos cenóbios organizados de modo linear. A variedade típica apresenta, por sua vez, células internas dispostas obliquamente e, conforme
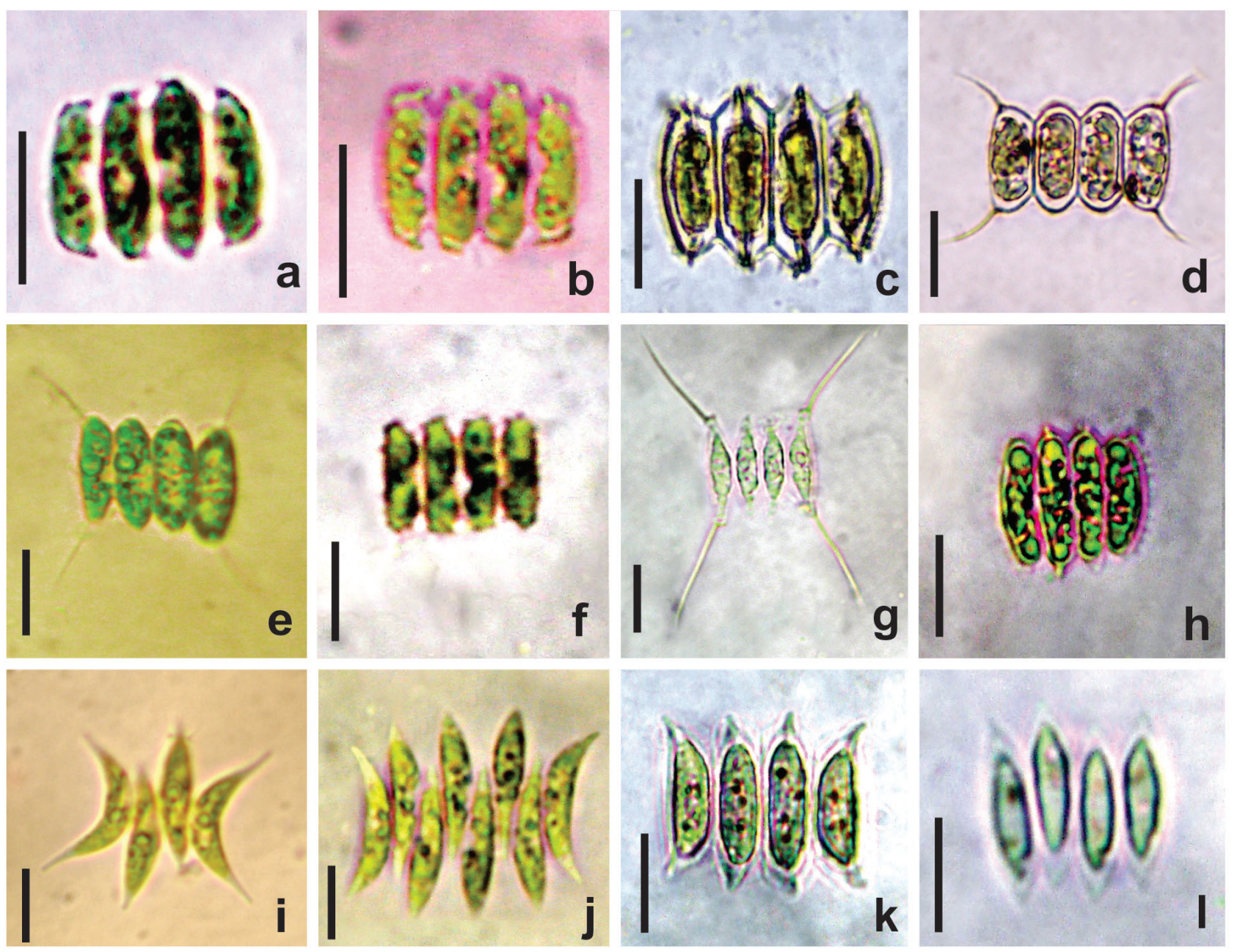

Figura 4 a-b. Desmodesmus arthrodesmiformis. c. D. brasiliensis. d-e. D. communis. f. D. granulatus. g. D. opoliensis var. mononensis. h. D. serratus. i-j. Acutodesmus acuminatus. k. A. dimorphus. 1. A. obliquus. Barras $=10 \mu \mathrm{m}$.

Figure 4 a-b. Desmodesmus arthrodesmiformis. c. D. brasiliensis. d-e. D. communis. f. D. granulatus. g. D. opoliensis var. mononensis. h. D. serratus. i-j. Acutodesmus acuminatus. k. A. dimorphus. 1. A. obliquus. Bars $=10 \mu \mathrm{m}$. 
Hegewald (1979), raramente é encontrada na natureza. Este é o primeiro registro da presença da variedade no Estado da Bahia.

Desmodesmus serratus (Corda) S.S. An, Friedl \& E. Hegewald, Algological Studies 96: 17. 2000. Figura $4 \mathrm{~h}$

Cenóbio plano, 4 células dispostas linearmente; células elípticas com polos arredondados, células externas com pequenos dentículos na margem lateral dispostos em uma fileira, as internas com um pequeno espinho nos polos; cloroplastídio 1, parietal, 1 pirenoide. Dimensões: célula 12,5-17,5 $\mu \mathrm{m}$ compr., 3,5-6,2 $\mu \mathrm{m}$ larg., espinho 1,5-2 $\mu \mathrm{m}$ compr.

Material examinado: BRASIL. BAHIA: Andaraí, Marimbus do Baiano, 1-IV-2011, C.W.N. Moura \& G.J.P. Ramos s.n. (HUEFS178327); 29-VI-2011, C.A. Ribeiro \& G.J.P. Ramos s.n. (HUEFS178362); 26-X-2011, C.A. Ribeiro \& G.J.P. Ramos s.n. (HUEFS185368); 10-II-2012, C.A. Ribeiro \& G.J.P. Ramos s.n. (HUEFS185411); Lençóis, Marimbus do Remanso, 30-VI-2011, C.A. Ribeiro \& G.J.P. Ramos s.n. (HUEFS178385, HUEFS178389, HUEFS178391, HUEFS178394); 27-X-2011, C.A. Ribeiro \& G.J.P. Ramos s.n. (HUEFS185385); 10-XII-2011, C.A. Ribeiro \& G.J.P. Ramos s.n. (HUEFS185398, HUEFS185400, HUEFS185401, HUEFS185404); 11-II-2012, C.A. Ribeiro \& G.J.P. Ramos s.n. (HUEFS185418, HUEFS185419, HUEFS185420, HUEFS185424, HUEFS185425).

Hábitat: perifíton.

Conforme Bortolini et al. (2010a), Desmodesmus serratus apresenta células elípticas a ovoides com pequenos espinhos em toda a margem das células externas, bem como 2 ou 3 espinhos nos polos de todas as células do cenóbio. Durante a análise do material coletado no Pantanal dos Marimbus foi observada a presença da margem serrilhada nas células externas e de um pequeno espinho apical, concordando com as observações realizadas por Godinho et al. (2010) para o material de São Paulo. Esse é o primeiro registro da espécie no Estado da Bahia.

\section{Scenedesmacae}

Acutodesmus - $\mathrm{O}$ gênero não tem um posicionamento definido (suportado por dados polifásicos) a nível de subfamília dentro das Scenedesmaceae.
Chave artificial para identificação das morfoespécies de Acutodesmus registradas no Pantanal dos Marimbus

1. Cenóbio com células externas fusiformes A. obliquus

1. Cenóbio com células externas de outros formatos (lunadas ou semilunadas)

2. Células externas semilunadas, margem reta ...... A. dimorphus

2. Células externas lunadas, margem côncava A. acuminatus

Acutodesmus acuminatus (Lagerheim) P.M. Tsarenko, Cryptogamie: Algologie 10(4): 176. 2000.

Figura 4 i-j

Cenóbio plano formado por 4-8 células dispostas de modo linear ou alternado; células internas fusiformes ou levemente curvas, células externas lunadas, polos afilados a pontiagudos; parede celular lisa; cloroplastídio 1, parietal, 1 pirenoide. Dimensões: célula 18,5-26,5 $\mu \mathrm{m}$ compr., 5-6,5 $\mu \mathrm{m}$ larg.

Material examinado: BRASIL. BAhia: Andaraí, Marimbus do Baiano, 1-IV-2011, C.W.N. Moura \& G.J.P. Ramos s.n. (HUEFS178332, HUEFS178341); 9-XII-2011, C.A. Ribeiro \& G.J.P. Ramos s.n. (HUEFS185388); Lençóis, Marimbus do Remanso, 2-IV-2011, C.W.N. Moura \& G.J.P. Ramos s.n. (HUEFS185354); 11-II-2012, C.A. Ribeiro \& G.J.P. Ramos s.n. (HUEFS185418).

Hábitat: plâncton, perifíton.

Acutodesmus acuminatus é comumente confundida com Pectinodesmus pectinatus (Meyen) Hegewald \& Wolf, sendo muitas vezes difícil a separação entre essas duas espécies, pois os principais caracteres morfológicos como a forma e arranjo das células geralmente se sobrepõem. Entretanto, segundo Hegewald et al. (2010) e Krienitz \& Bock (2012) o gênero Pectinodesmus apresenta fortes ornamentações longitudinais na parede celular, evidenciadas principalmente em MEV, como principal característica morfológica que o distingue de Acutodesmus. Durante as nossas análises não observamos exemplares com parede ornamentada, portanto, decidimos identificar essa espécie como Acutodesmus acuminatus.

Os espécimes coletados no Pantanal dos Marimbus apresentaram variação morfológica no grau de curvatura das células externas, que apareceram ora mais ora menos lunadas; e com referência ao ápice das células, que variou desde afilado até pontiagudo. 
Acutodesmus dimorphus (Turpin) P.M. Tsarenko, Cryptogamie: Algologie 10(4): 176. 2000.

Figura $4 \mathrm{k}$

Cenóbio plano formado por 4 células; células dispostas de modo linear, células fusiformes; células externas semilunadas, margem reta, células internas fusiformes, polos afilados, curvados; parede celular lisa; cloroplastídio 1, parietal, 1 pirenoide. Dimensões: célula 8,5-21 $\mu \mathrm{m}$ compr., 3,5-6,5 $\mu \mathrm{m}$ larg.

Material examinado: BRASIL. BAHIA: Lençóis, Marimbus do Remanso, 10-XII-2011, C.A. Ribeiro \& G.J.P. Ramos s.n. (HUEFS185400); 10-II-2012, C.A. Ribeiro \& G.J.P. Ramos s.n. (HUEFS185418, HUEFS185421, HUEFS185425).

Hábitat: perifíton.

A espécie é caracterizada por apresentar células externas semilunadas, com margem reta e polos afilados e curvos. Devido a isso, A. dimorphus é comumente confundida com $A$. acuminatus, porém, esta difere por apresentar células externas lunadas, com margem côncava. Os espécimes de $A$. dimorphus provenientes do Pantanal dos Marimbus estão, morfologicamente, de acordo com os analisados por Comas (1996), Moresco \& Bueno (2007) e Tsarenko \& John (2011). Esse é o primeiro registro da espécie no Estado da Bahia.

Acutodesmus obliquus (Turpin) E. Hegewald \& Hanagata, Cryptogamie: Algologie 10(4): 176. 2000.

Figura 41

Cenóbio plano formado por 4 células dispostas linearmente, às vezes levemente alternadas; células internas e externas fusiformes, polos afilados, retos; parede celular lisa; cloroplastídio 1, parietal, 1 pirenoide. Dimensões: célula 11,5-18,5 $\mu \mathrm{m}$ compr., 2,5-5 $\mu \mathrm{m}$ larg.

Material examinado: BRASIL. BAHIA: Andaraí, Marimbus do Baiano, 1-IV-2011, C.W.N. Moura \& G.J.P. Ramos s.n. (HUEFS178327, HUEFS178335); 29-VI-2011, C.A. Ribeiro \& G.J.P. Ramos s.n. (HUEFS178372, HUEFS178374, HUEFS178379); 19-VIII-2011, C.W.N. Moura \& G.J.P. Ramos s.n. (HUEFS185348, HUEFS185352, HUEFS185353); 26-X-2011, C.A. Ribeiro \& G.J.P. Ramos s.n. (HUEFS185374, HUEFS185375, HUEFS185376, HUEFS 185377); 9-XII-2011, C.A. Ribeiro \& G.J.P. Ramos s.n. (HUEFS185398, HUEFS185400,
HUEFS185401, HUEFS185402, HUEFS185404); 10-II-2012, C.A. Ribeiro \& G.J.P. Ramos s.n. (HUEFS185408); Lençóis, Marimbus do Remanso, 2-IV-2011, C.W.N. Moura \& G.J.P. Ramos s.n. (HUEFS178346, HUEFS178354); 30-VI-2011, C.A. Ribeiro \& G.J.P. Ramos s.n. (HUEFS178380, HUEFS178385, HUEFS178387, HUEFS178389, HUEFS178391, HUEFS178393); 20-VIII-2011, C.W.N. Moura \& G.J.P. Ramos S.n. (HUEFS185358, HUEFS185359, HUEFS185362, HUEFS185364, HUEFS185367); 27-X-2011, C.A. Ribeiro \& G.J.P. Ramos s.n. (HUEFS 185378 , HUEFS 185379 , HUEFS185381, HUEFS185382, HUEFS185384, HUEFS185385, HUEFS185386); 10-XII-2011; C.A. Ribeiro \& G.J.P. Ramos s.n. (HUEFS185388, HUEFS185390, HUEFS185392, HUEFS185395); 11-II-2012, C.A. Ribeiro \& G.J.P. Ramos s.n. (HUEFS185418, HUEFS185426, HUEFS185427).

Hábitat: plâncton, perifíton.

Nas populações estudadas no Pantanal dos Marimbus foi detectada variação morfológica relacionada aos ápices das células externas, variando desde retos até levemente curvos, como já havia sido documentado por Uherkovich (1966) para Hungria, Sant'Anna (1984) para São Paulo e Comas (1996) para Cuba. Observou-se uma variação também no arranjo das células no cenóbio que, embora predominantemente linear, apresentou alguns exemplares com células levemente deslocadas.

Considerando a ocorrência dos representantes de Scenedesmaceae notou-se que todos os táxons ocorreram nas duas áreas dos Marimbus, exceto Coelastrum astroideum, C. proboscideum e Desmodesmus armatus var. bicaudatus que tiveram distribuição exclusiva no Marimbus do Baiano, e Coelastrum cruciatum e C. pseudomicroporum, ocorrentes apenas no Marimbus do Remanso.

Em relação ao tipo de hábitat, todos os táxons tiveram ocorrência registrada na comunidade perifítica, nenhum teve ocorrência exclusiva no plâncton e 11 foram comuns as duas comunidades. Westella botryoides e Scenedesmus ecornis foram as espécies com a maior distribuição nas duas áreas de estudo.

A partir deste estudo foi ampliada a distribuição geográfica da família Scenedesmaceae para o Brasil, de modo que 18 táxons são novos registros para a Bahia (Acutodesmus dimorphus, A. obliquus, Coelastrum cruciatum, C. proboscideum, C. pseudomicroporum, C. pulchrum, Comasiella arcuata var. platydisca, 
Desmodesmus aculeolatus, D. armatus var. armatus, $D$. armatus var. bicaudatus, D. arthrodesmiformis, D. granulatus, D. opoliensis var. monoensis, D. serratus, Scenedesmus acunae, S. ellipticus, S. obtusus e Verrucodesmus verrucosus).

\section{Agradecimentos}

Gostaríamos de agradecer Coordenação de Aperfeiçoamento de Pessoal do Ensino Superior (CAPES) pela concessão da bolsa de Mestrado do primeiro Autor, à Universidade Estadual de Feira de Santana (UEFS) pelo auxilio logístico, a Camila dos Anjos Ribeiro pelo auxílio nas coletas e ao Projeto Ecológico de Longa Duração (PELD Chapada Diamantina) (MCT/CNPq n ${ }^{\circ}$ 59/2009), pelo financiamento das coletas.

\section{Literatura citada}

An, S.S., Friedl, T. \& Hegewald, E. 1999. Phylogenetic relationships of Scenedesmus and Scenedesmus-like coccoid green algae as referred from ITS-2 rDNA sequence comparisons. Plant Biology 1: 418-428.

Atkinson, A.W., Gunning, B.E.S. \& John, P.L.C. 1972. Sporopolenin in the cell wall of Chlorella and other algae: ultrastructure, chemistry and incorporation of 14C-acetate, studied in synchronous cultures. Planta 107: 1-32.

Bicudo, C.E.M. \& Menezes, M. 2006. Gêneros de algas de águas continentais do Brasil: chave para identificação e descrições. 2 ed. RiMa, São Carlos.

Bock, C., Luo, W., Kusber, W.-H., Hegewald, E., Pazoutová, M. \& Krienitz, L. 2013. Classification of crucigenoid algae: phylogenetic position of the reinstated genus Lemmermannia, Tetrastrum spp. Crucigenia tetrapedia, and C. lauternornii (Trebouxiophyceae, Chlorophyta). Journal of Phycology 49: 3290339.

Bortolini, J.C., Meurer, T., Godinho, L.R. \& Bueno, N.C. 2010a. Chlorococcales planctônicas do Rio São João, Parque Nacional do Iguaçu, Paraná, Brasil. Hoehnea 37:315-330.

Bortolini, J.C., Biolo, S., Bueno, N.C., Godinho, L.R. \& Pott, V.J. 2010b. Chlorococcales sensu lato (Chlorophyceae) em tanques de depuração de efluente de origem bovina no Mato Grosso do Sul, Brasil. Iheringia: Série Botânica 65: 63-74.

Comas, A. 1996. Las Chlorococcales dulciacuícolas de Cuba. Biblioteca Phycologica 99: 1-265.

Domingues, C.D. \& Torgan, L.C. 2012. Chlorophyta de um lago artificial hipereutrófico no sul do Brasil. Iheringia: Série Botânica 67: 75-91.

Felisberto, S.A., Rodrigues, L. \& Leandrini, J.A. 2001. Chlorococcales registradas na comunidade perifítica, no reservatório de Corumbá, Estado de Goiás, Brasil, antes e após o represamento das águas. Acta Scientiarum, Biological Sciences 23: 275-282.
Ferragut, C., Lopes, M.R.M., Bicudo, D.C., Bicudo, C.E.M., \& Vercellino, I.S. 2005. Ficoflórula perifítica e planctônica (exceto Bacillariophyceae) de um reservatório oligotrófico raso (Lago do IAG, São Paulo). Hoehnea 32: 137-184.

Fuentes, E.V., Oliveira, H.S.B., Cordeiro-Araújo M.K., Severi W. \& Moura, A.N. 2010. Variação Espacial e Temporal do Fitoplâncton do Rio de Contas, Bahia, Brasil. Revista Brasileira de Engenharia de Pesca 5: 13-25.

Godinho, L.R., Comas, A. \& Bicudo, C.E.M. 2010. Criptógamos do Parque Estadual das Fontes do Ipiranga, São Paulo, SP. Algas, 30: Chlorophyceae (família Scenedesmaceae). Hoehnea 37: 513-553.

Hegewald, E. 1979. Vergleichende Beobachtungen an Herbarmaterial und Freilandmaterial von Scenedesmus. Algological Studies 24: 264-286.

Hegewald, E. 2000. New combinations in the genus Desmodesmus (Chlorophyceae, Scenedesmaceae). Algological Studies 96: 1-18.

Hegewald, E. \& Silva, P. 1988. Annotated catalogue of Scenedesmus and nomenclaturally related genera, including original descriptions and figures. Bibliotheca Phycologica 80: 1-587.

Hegewald, E. \& Wolf, M. 2003. Phylogenetic relationships of Scenedesmus and Acutodesmus (Chlorophyta, Chlorophyceae) as infered from $18 \mathrm{~S}$ rDNA and ITS- 2 sequence comparisons. Plant Systematics and Evolution 241: 185-191.

Hegewald, E., Wolf, M., Keller, A., Friedl, T. \& Krienitz, L. 2010. ITS2 sequence-structure phylogeny in the Scenedesmaceae with special reference to Coelastrum (Chlorophyta, Chlorophyceae), including the new genera Comasiella and Pectinodesmus. Phycologia 49: 325-335.

Hegewald, E., Bock, C. and Krienitz, L. 2013. A phylogenetic study on Scenedesmaceae with the description of a new species of Pectinodesmus and the new genera Verrucodesmus and Chodatodesmus (Chlorophyta, Chlorophyceae). Fottea, 13: 149-164.

Hentschke, G.S. \& Torgan, L.C. 2010a. Chlorococcales lato sensu (Chlorophyceae, excl. Desmodesmus e Scenedesmus) em ambientes aquáticos na Planície Costeira do Rio Grande do Sul, Brasil. Iheringia: Série Botânica, 65: 87-100.

Hentschke, G.S. \& Torgan, L.C. 2010b. Desmodesmus e Scenedesmus (Scenedesmaceae, Sphaeropleales, Chlorophyceae) em ambientes aquáticos na Planície Costeira do Rio Grande do Sul, Brasil. Rodriguésia 61: 585-601.

Hindák, F. 1990. Studies on the chlorococcal algae (Chlorophyceae), 5. Biologické Práce 36:1-225.

Komárek, J. 1983. Contribution to the chlorococcal algae of Cuba. Nova Hedwigia 37: 65-180. 
Komárek, J. \& Fott, B. 1983. Chlorophyceae (grünalgen) Ordnung: Chlorococcales. In: Huber-Pestalozzi, G. (eds.). Das Phytoplankton des Süsswassers: Systematic und Biologie. E. Schweizerbart'sche Verlagsbuchhandling (Nägele u. Obermiller), Stuttgart, pp. 1-1044.

Krienitz, L. \& Bock, C. 2012. Present state of the systematics of planktonic coccoid green algae of inland waters. Hydrobiologia. Published online: 1-32.

Martins, D.V., Sant'Anna, C.L. \& Oliveira, O.C. 1991. Estudo qualitativo do fitoplâncton do Dique do Tororó, Salvador, Bahia, Brasil. Revista Brasileira de Biologia 51: 445-453.

Mendes, M.C.Q., Comas, A., Menezes, M., Nunes, J.M.C., Pereira, S. \& Nascimento, I.A. 2012. Coleção de microalgas de ambientes dulciaquícolas naturais da Bahia, Brasil, como potencial fonte para a produção de biocombustíveis: uma abordagem taxonômica, Acta Botanica Brasilica 26: 691-696.

Menezes, M., Tucci, A., Peres, C.K., Fajar, A. \& Branco, C.Z. 2014. Chlorophyceae. In: Forzza, R. et al. Lista de Espécies da Flora do Brasil. Jardim Botânico do Rio de Janeiro. Disponível em http://floradobrasil.jbrj.gov.br/ jabot/floradobrasil/FB118453 (acesso em: 02-VI-2014).

Moresco, C. \& Bueno, N.C. 2007. Scenedesmaceae (Chlorophyceae, Chlorococcales) de um lago artificial urbano: Desmodesmus e Scenedesmus. Acta Scientiarum, Biological Sciences 29: 289-296.

Nogueira, I.S. 1991. Chlorococcales sensu lato (Chlorophyceae) do Município do Rio de Janeiro e arredores, Brasil: inventário e considerações taxonômicas. Dissertação de Mestrado, Universidade Federal do Rio de Janeiro, Rio de Janeiro.
Ramos, G.J.P., Bicudo, C.E.M., Góes-Neto, A. \& Moura, C.W.N. 2014. New additions of coccoid green algae to the phycoflora of Brazil and the Neotropics. Acta Botanica Brasilica 28: 8-16.

Rodrigues, L.L., Sant'Anna, C.L. \& Tucci, A. 2010. Chlorophyceae das Represas Billings (Braço Taquacetuba) e Guarapiranga, SP, Brasil. Revista Brasileira de Botânica 33: 247-264.

Sant'Anna, C.L. 1984. Chlorococcales (Chlorophyceae) do Estado de São Paulo, Brasil. Berlin: J. Cramer. (Bibliotheca Phycologica 67).

Severiano, J.S., Moura, A.N., Oliveira, H.S.B., Cordeiro-Araújo, M.K. \& Dantas, E.W. 2012. Microphytoplankton richness in Contas River, state of Bahia, northeastern Brazil. Check List 8: 218-223.

Souza, D.B.S. \& Felisberto, S.A. 2014. Comasiella, Desmodesmus, Pectinodesmus e Scenedesmus na comunidade perifítica em ecossistema lêntico tropical, Brasil Central. Hoehnea, 41: 109-120.

Tsarenko, P.M. \& Petlevanny O.A. 2001 Doplolneniek "Raznoobraziju vodoroslej Ukrainy". Algologia, Supplement 1-130.

Tsarenko, P.M. \& John, D.M. 2011. Phylum Chlorophyta (Green Algae) Order Sphaeropleales In: John, D.M., Whitton, B.A. \& Brook, A.J. (eds.). The Freshwater Algal Flora of the British Isles, 2 ed., Cambridge University Press. pp. 461-465.

Uherkovich, G. 1966. Die Scenedesmus-Arten Ungarns. Akademiai Kiadó, Budapest. 